DOI 10. 18307/2019. 0618

(C) 2019 by Journal of Lake Sciences

\title{
海南东部小海潟湖沉积物地球化学特征及对古台风活动的指示
}

\author{
游爱华 ${ }^{1}$, 薛积涁 ${ }^{1 * *}$, 谢露华 ${ }^{2}$, 程 嵘 $^{1}$, 魏志强 ${ }^{1}$, 钟 巍 ${ }^{1}$ \\ (1: 华南师范大学地理科学学院,广州 510631) \\ (2:中国科学院广州地球化学研究所,广州 510640)
}

\begin{abstract}
摘 要: 为探讨海南东部历史时期的气候环境变化, 2015 年于海南岛东海岸小海潟湖中采集了一根长 $73 \mathrm{~cm}$ 的柱状样 (XH15-02), 在年代学 $\left({ }^{210} \mathrm{~Pb}\right.$ 和 $\left.\mathrm{AMS}^{14} \mathrm{C}\right)$ 测试的基础上,开展了多环境代用指标 (总有机碳 ( TOC) 、总氮 ( TN )、有机碳稳 定同位素、干密度等) 的测试和分析. 结果表明, XH15-02 柱状样 TOC 与 TN 含量有很好的相关性, C/N 比值在 10.41 23.33 之间变化, 有机碳稳定同位素 $\left(\delta^{13} \mathrm{C}_{\mathrm{org}}\right)$ 值在 $-25.14 \% 0 \sim-23.29 \%$ 之间. 通过对多气候环境代用指标的分析, 以及与 历史文献资料和其他自然代用指标的综合比对, 认为 XH15-02 孔岩芯沉积记录了研究区过去 1100 多年来较为丰富的气 候环境、台风活动以及人类活动影响等信息. 近千年来, 小海潟湖沉积有机物主要以陆源输人为主, 据估算该岩芯有机碳 陆生来源约占 $47.00 \% \sim 73.43 \%$, 但在不同时期变化幅度较大, 该陆源有机碳含量变化可能主要反映了历史时期海南东部 地区的干湿变化历史; 自 1850 年以来, XH15-02 孔岩芯沉积通量的显著增加与当地人口的快速增长历史一致, 反映了研 究区近二百年来可能受到的人类对自然界的开发活动影响强烈; 多个具有显著偏正 $\delta^{13} \mathrm{C}_{\mathrm{org}}$ 记录的时期同史料记载以及 周边区域地质记录中的 “大风”、“海溢”、“风暴” 等事件发生时间较为相近, 可能揭示了历史时期的台风或高海平面事 件,进而认为小海潟湖沉积在重建历史时期海南地区台风活动等方面具有很大潜力.
\end{abstract}

关键词: 小海潟湖;有机碳同位素; 人类活动; 强台风

\section{Geochemical characteristics of sediments in the Xiaohai lagoon (Eastern Hainan) and implications for the paleo-typhoon activities}

\author{
YOU Aihua ${ }^{1}$, XUE Jibin $^{1 * *}$, XIE Luhua ${ }^{2}$, CHENG Rong ${ }^{1}$, WEI Zhiqiang ${ }^{1} \&$ ZHONG Wei $^{1}$ \\ (1: School of Geographical Sciences, South China Normal University, Guangzhou 510631, P.R. China) \\ (2: Guangzhou Institute of Geochemistry, Chinese Academy of Sciences, Guangzhou 510640, P.R.China)
}

Abstract: Coastal lagoons with small catchment influenced both by seawater and river inflow, are highly sensitive to natural processes and anthropogenic activities, which make it ideal regions to study the paleo-environmental and paleo-climatic changes. To better understand the past climatic and environmental changes of the eastern Hainan Island, a $73 \mathrm{~cm}$-long sediment core (XH15-02 core) was collected from the Xiaohai Lagoon, eastern Hainan Island in January, 2015. ${ }^{210} \mathrm{~Pb}$ and $\mathrm{AMS}^{14} \mathrm{C}$ dates were determined, respectively, and multiple proxies including the total organic carbon ( TOC), total nitrogen (TN), organic carbon stable isotopes $\left(\delta^{13} \mathrm{C}_{\mathrm{org}}\right)$, and dry density, were analyzed. In addition, based on the data mentioned above, deposition rate and flux of sediment and organic carbon were calculated, respectively. The results show that there is a good correlation between the content of TOC and $\mathrm{TN}$; the ratios of $\mathrm{C} / \mathrm{N}$ show remarkable variations ranging from $10.41-23.33$, and $\delta^{13} \mathrm{C}_{\text {org }}$ values vary between $-25.14 \%$ and $-23.29 \%$; and the proportion of terrestrial organic carbon sources vary from $47.00 \%$ to $73.43 \%$ with some obvious low values during the last 1100 years, the terrestrial organic carbon content may record the precipitation changes in the eastern Hainan during the last millennium. Deposition rate and flux of sediment and organic carbon were relatively steady before 1850s, however, it increased rapidly after $1850 \mathrm{~s}$, especially since 1950s. The significant accelerated sedimentation process during the last two hundred years was probably related to the population growth and intensified anthropogenic activities in the Hainan Island at the same period. Based on the analysis of multi-proxies and comparison with the historical literature records and other climatic records from other regions, we

* 国家自然科学基金面上项目 (41671194) 和华南师范大学研究生创新计划项目联合资助. 2019-02-28 收稿; 201905-07 收修改稿. 游爱华 (1992 ), 女, 硕士研究生;E-mail: 2016022023@ m.scnu.edu.cn.

** 通信作者; E-mail: jbxue@ scnu.edu.cn. 
assume that the XH15-02 core sediment drilled from the Xiaohai Lagoon may record some high sea level and/or strong typhoon events during the historical period. Especially, our results suggest that the $\delta^{13} \mathrm{C}_{\text {org }}$ records of XH15-02 core may be a valuable proxy to reconstruct the paleo-typhoon activities during the last millennium.

Keywords: Xiaohai Lagoon; organic carbon stable isotopes; anthropogenic activities; strong typhoons

海岸带地区是重要的人口集聚地, 也是全球经济发展最有活力的地区, 但自然灾害和人为因素造成的 生态环境破坏常给沿海地区造成巨大的损失. 正确认识不同区域不同时期的气候环境演变和人类活动对自 然过程的改造是探索气候环境变化规律、预测未来可能发生的自然灾害进而规避风险和创造价值的前提, 特别是在当前全球气候变暖的大背景下,这一问题显得更为重要. 潟湖是沿海地区物质沉积的理想场所, 能 够滞留外部海水及人湖径流携带的物质 ${ }^{[1-2]}$. 由于潟湖水动力条件相对河流与海洋而言较弱, 沉积物可以很 好地保存下来, 因而潟湖沉积能够很好地记录当时当地的气候水文或人为活动引起的环境变化信息 ${ }^{[3-5]}$, 诸 如台风、人类活动、河流水量和潟湖口门变化等因素引起的环境变化大都可以从潟湖沉积物中寻得一些 踪迹 ${ }^{[4-7]}$.

海南省位于中国大陆最南端, 是中国最大且唯一的省级经济特区, 在国家发展战略中的重要地位日益 凸显. 然而, 海南岛也是我国受热带气旋活动影响最为严重的地区之一. 据统计, 近 40 年来海南平均每年约 有 7 个热带气旋影响、2.4 个热带气旋登陆 ${ }^{[8]}$, 经常给该地区带来重大社会经济损失和人员伤亡. 在当前全 球变暖背景下, 影响海南地区的热带气旋活动将会出现何种变化? 由于历史上海南岛距离国家政治中心 远、经济地位不突出, 历史文献记载较为稀少, 仅近 500 年来相关记载较为丰富, 因而寻找和利用一些合适 的自然载体 (如海岸带潟湖沉积物) 并从中提取历史时期海南地区的气候环境变化规律和特征就显得尤为 必要. 海南东部沿海分布了众多的海岸潟湖, 其中, 地处万宁市境内的小海潟湖是海南岛最大的潟湖, 为研 究海南地区的气候环境演变、自然灾害以及人类活动影响等提供了良好的研究载体 ${ }^{[9-11]}$. 目前, 针对小海潟 湖的研究主要集中在近百年左右的沉积环境特征与演变 ${ }^{[9-11]}$ 、环境破坏与工程治理 ${ }^{[12-13]}$ 、潮汐特征与水位变 化 ${ }^{[14-15]}$ 等方面, 仍缺乏较长时间尺度的环境变化研究. 本文拟通过对小海潟湖沉积物中总有机碳 (TOC) 含 量、总氮 $(\mathrm{TN})$ 含量、 $\mathrm{C} / \mathrm{N}$ 比值、有机碳稳定同位素 $\left(\delta^{13} \mathrm{C}_{\mathrm{org}}\right) 、 干$ 密度等指标的测试分析, 揭示各地球化学指标 可能蕴含的气候环境指示意义, 进而重建该地区历史时期以来的气候环境变化过程.

\section{1 研究区概况}

小海潟湖地处海南省万宁市境内 (图 1), 属热带季风气候, 年平均气温为 $24^{\circ} \mathrm{C}$, 年平均降雨量为 2400 $\mathrm{mm}$ 左右. 该地区在夏秋季节受热带气旋影响频繁, 自 1950 年以来,平均每十年有 4.7 次至少热带风暴级别 的热带气旋直接登陆万宁境内,而台风期间引发的台风增水极值可达 $1.67 \mathrm{~m}^{[16]}$. 小海潟湖现代水域面积约 为 $46 \mathrm{~km}^{2}$, 是海南省境内最大的潟湖湾, 呈腹大口小的葫芦状, 海岸类型为典型的沙坝一潟湖海岸. 该潟湖发 育初期可能由一系列断续岛状沙堤环抱而成, 有多条通道与外海联通 ${ }^{[16]}$, 但目前仅有潟湖东北角有一条单 一通道与南海相通. 小海潟湖属咸水湖, 潟湖外海水体 (属南海水体) 的盐度一般在 33\%o左右, 潟湖内的平 均盐度由北向南递减, 潟湖潮汐汉道区平均盐度为 $8.6 \%$ $31.0 \%$, 由潮汐通道口门至潟湖上游盐度逐渐变 小, 涨潮期间盐度大, 落潮期间盐度小 ${ }^{[10]}$. 自 1973 年口门北侧修建防沙堤之后, 南沙嘴快速发展使口门不断 束窄, 目前口门的宽度只有 $30 \mathrm{~m}$ 左右 ${ }^{[15]}$. 小海潟湖湾内大部分水深在 $1.0 \sim 1.5 \mathrm{~m}$ 之间, 湖底略向南倾斜, 湾 北的盐墩村西北沟槽处和潟湖中心低洼处较深. 潟湖四周地势平坦, 仅南面见花岗岩残丘, 如东山岭、后山 岭、大长岭等. 流域内水系发达, 有多条河流入湖, 如龙头河、龙尾河、东山河、港北河、白石溪等, 原小海潟湖 最大的补给径流太阳河已于 1972 年经人工改道而直流南海, 干流不再人湖 ${ }^{[16]}$.

\section{2 材料与方法}

课题组于 2015 年 1 月在小海潟湖西南部使用活塞取样器采集了 2 个柱状样岩芯 (XH15-01 和 XH15$02)$, 本文主要对 XH15-02 孔岩芯 $\left(18^{\circ} 49^{\prime} 11^{\prime \prime} \mathrm{N}, 110^{\circ} 27^{\prime} 12^{\prime \prime} \mathrm{E}\right.$; 采样点水深约为 $1.4 \mathrm{~m}$, 位置见图 1) 开展了年 代学和多代用指标的实验分析. XH15-02 孔岩芯长度为 $73 \mathrm{~cm}$, 以 $2 \mathrm{~cm}$ 间距取样进行总有机碳 (TOC) 含量、 
总氮 $(\mathrm{TN})$ 含量和 $\delta^{13} \mathrm{C}_{\mathrm{org}}$ 测定, 以 $1 \mathrm{~cm}$ 间距做干密度分析. 根据干密度、沉积速率和有机碳测试结果计算该 孔岩芯沉积物沉积通量和有机碳沉积通量. 对岩芯上部 $30 \mathrm{~cm}$ 以 $1 \mathrm{~cm}$ 间距取样, 经冷冻干燥、略微研磨后进 行 ${ }^{210} \mathrm{~Pb}$ 年代测试, 该测试在中国科学院南京地理与湖泊研究所完成. 采用恒定比活度模式 (Constant Rate of Supply, 简称 CRS 模式) 建立顶部 $30 \mathrm{~cm}$ 沉积物年代序列 ${ }^{[17]}$. 此外, 在距离顶部 $18 、 42 、 57 、 70 \mathrm{~cm}$ 处取样进行 加速质谱 $(\mathrm{AMS}){ }^{14} \mathrm{C}$ 年代测试, 由美国 BETA 实验室完成, 测年误差为 \pm 30 a. 最后, 使用 Bacon 软件 ${ }^{[18-20]}$ 对 获得的 $\mathrm{AMS}^{14} \mathrm{C}$ 年代结果进行日历年校正.

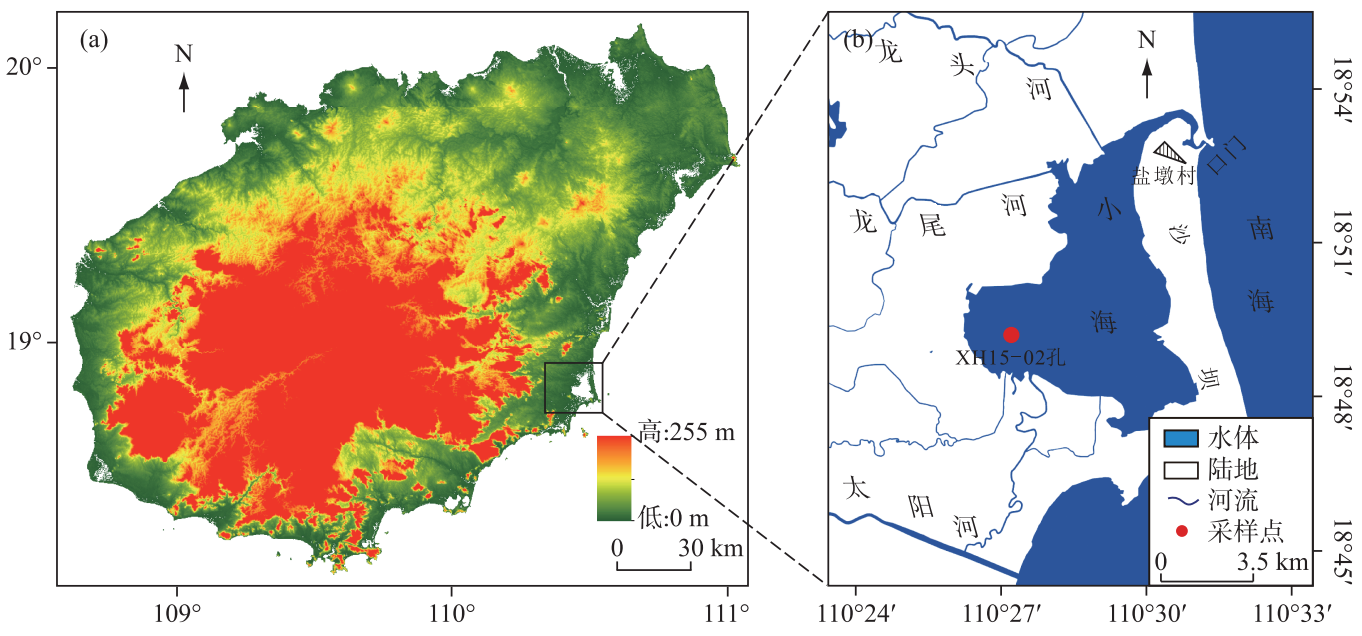

图 1 小海潟湖在海南省的位置 (a) 与岩芯采样点位置 (b) 示意图

Fig.1 Study area and the location of sampling site

沉积物 TOC、TN 和 $\delta^{13} \mathrm{C}_{\mathrm{org}}$ 测试的前处理过程 ${ }^{[21]}$ 大致如下: 取适量样品加人 $5 \%$ 浓度的稀盐酸 ( HCl) 去 除碳酸盐; 用蒸馏水清洗样品, 使其呈中性; 之后进行冷冻干燥、研磨至粉末状并过 150 目䇻, 然后取适量样 品包人锡舟后放人自动进样器使用英国 Isoprime 公司生产的稳定同位素质谱仪 ( Isoprime 100 型) 连接德国 Elementar 公司生产的元素分析仪 (Vario PYRO cube 型) 进行分析测试,测试精度分别为 5\%、5\%和 $0.15 \%$ ， $\delta^{13} \mathrm{C}_{\text {org }}$ 分析结果采用 V-PDB 标准, 该测试在中国科学院广州地球化学研究所完成.

\section{3 结果}

\section{1 年代}

因 XH15-02 孔岩芯的 ${ }^{210} \mathrm{~Pb}$ 比活度在距顶部 $21 \mathrm{~cm}$ 处基本达到稳定,故而采用 CRS 模式建立 XH15-02 柱状岩芯上部 $21 \mathrm{~cm}$ 的年代序列, 其对应年代为 $1839-2013 \mathrm{AD}$ (图 $2 \mathrm{a}$ ). $\mathrm{AMS}^{14} \mathrm{C}$ 测年结果列于表 1 . 综合 $\mathrm{AMS}^{14} \mathrm{C}$ 和 ${ }^{210} \mathrm{~Pb}$ 两种测试结果发现, 距离顶部 $18 \mathrm{~cm}$ 处的 ${ }^{210} \mathrm{~Pb}$ 年代为 $1933 \mathrm{AD}$, 而同一层位的 $\mathrm{AMS}^{14} \mathrm{C}$ 年代 为 $1670 \mathrm{AD}$, 由此确定小海潟湖沉积物的碳库年龄大致为 263 年. 使用 Bacon 软件 ${ }^{[18-20]}$, 选取 Marine13 作为 该年代-深度模型的校正曲线, 对 $\mathrm{AMS}^{14} \mathrm{C}$ 测年数据进一步进行碳库校正和日历年校正, 进而建立整个岩芯 的沉积年代序列 (图 2b). 最终结果表明,XH15-02 孔岩芯大致记录了过去 1100 年 (910-2013 AD) 以来的 气候环境变化信息.

\subsection{TOC、TN、C $/ \mathrm{N} 、 \delta^{13} \mathrm{C}_{\text {org }}$ 值和干密度}

XH15-02 孔岩芯 TOC、TN、C/N、 $\delta^{13} \mathrm{C}_{\text {org }}$ 值和干密度分析结果如图 3 所示. XH15-02 孔岩芯 TOC 含量在 $0.39 \% \sim 1.09 \%$ 之间,整体变幅不大,但峰谷转换明显,平均值约为 $0.71 \%$, 表层到 $14 \mathrm{~cm}$ 深度 TOC 含量均在 $0.90 \%$ 以上, 在 $38 \mathrm{~cm}$ 和 $40 \mathrm{~cm}$ 处达到剖面较低值, 分别为 $0.39 \%$ 和 $0.45 \%$. XH15-02 孔岩芯 TN 含量在 $0.03 \% \sim 0.11 \%$ 之间, 平均含量约为 $0.054 \%$. TOC 与 $\mathrm{TN}$ 的相关性系数为 0.80 (置信水平为 0.95 ), 两者变化基 本一致. $\mathrm{C} / \mathrm{N}$ 比值变化介于 $10.41 \sim 23.33$ 之间, 平均值约为 16.08 , 由表层到 $34 \mathrm{~cm}$ 处变化比较频繁, 由 $36 \mathrm{~cm}$ 
至岩芯底部变化比较稳定, 但在 $46 \mathrm{~cm}$ 和 $62 \mathrm{~cm}$ 处 $\mathrm{C} / \mathrm{N}$ 比值较高, 分别达到 22.78 和 20.07. $\delta^{13} \mathrm{C}_{\text {org }}$ 值变化范 围为 $-25.14 \% 0 \sim-23.29 \%$, 平均值约为 $-24.30 \%$, 在 $44 \mathrm{~cm}$ 和 $62 \mathrm{~cm}$ 处分别达到最低值和最高值. 干密度值在 $1.17 \sim 2.29 \mathrm{~g} / \mathrm{cm}^{3}$ 之间变化,平均值约为 $1.69 \mathrm{~g} / \mathrm{cm}^{3}$.

表 1 XH15-02 孔 AMS ${ }^{14} \mathrm{C}$ 测年结果

Tab. 1 AMS ${ }^{14} \mathrm{C}$ dating results of the XH15-02 core

\begin{tabular}{cccccccc}
\hline 实验室编号 & 样品编号 & 深度/cm & ${ }^{14} \mathrm{C}$ 年龄/BP & 误差/a & 碳库年龄/a & 校正曲线 & 校正年龄/ (cal. $\mathrm{aBP})$ \\
\hline Beta-449369 & XH15-02-18 & 18 & 280 & \pm 30 & 263 & Marine13 & $12-240$ \\
Beta-404213 & XH15-02-42 & 42 & 850 & \pm 30 & 263 & Marine13 & $378-595$ \\
Beta-449370 & XH15-02-57 & 57 & 1400 & \pm 30 & 263 & Marine13 & $742-1023$ \\
Beta-404214 & XH15-02-70 & 70 & 1630 & \pm 30 & 263 & Marine13 & $1035-1309$ \\
\hline
\end{tabular}
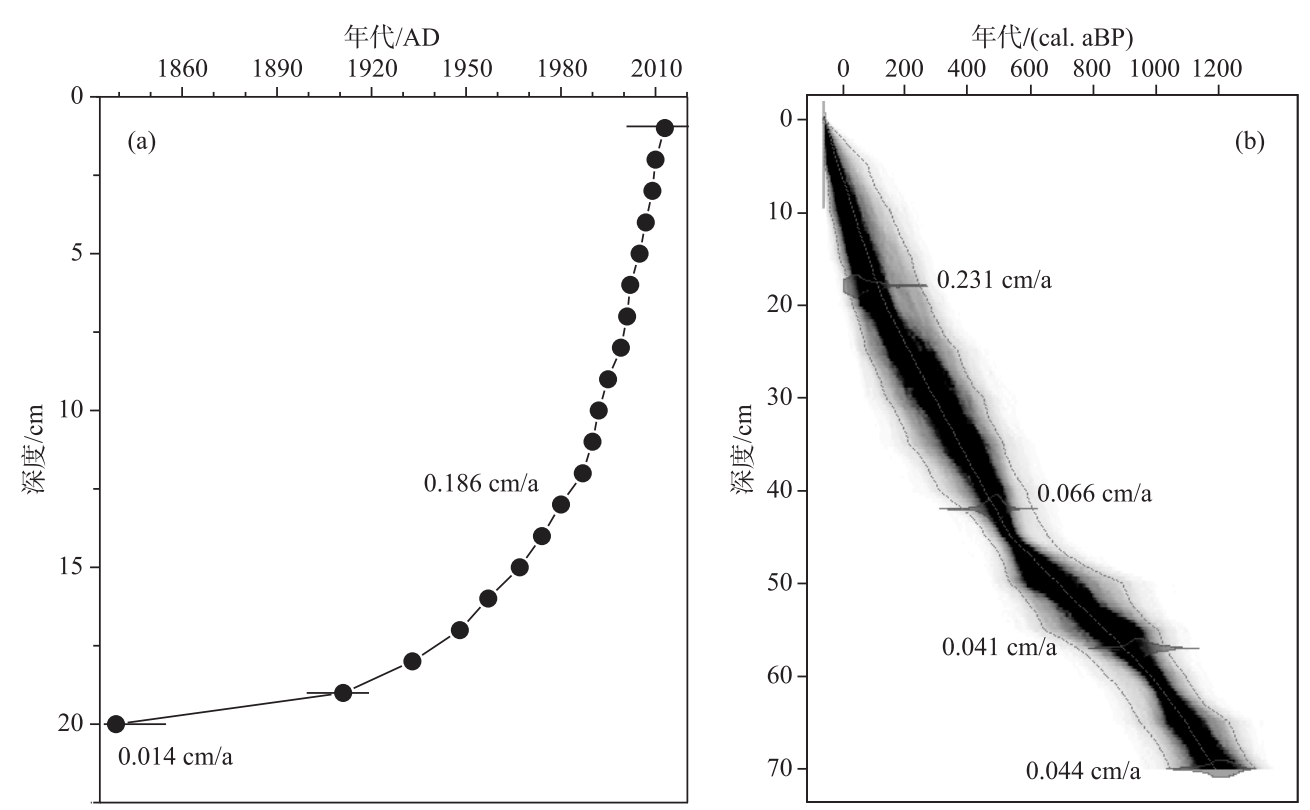

图 2 XH15-02 孔岩芯年代-深度模型

Fig.2 Age-depth model of the XH15-02 core

\section{4 讨论}

\section{1 小海沉积物中不同来源有机碳所占比例的估算}

在湖泊、河口或者三角洲等自然环境系统内,沉积物来源不同是导致沉积物中有机质 $\mathrm{C} / \mathrm{N}$ 比值和 $\delta^{13} \mathrm{C}_{\mathrm{org}}$ 不同的直接原因, $\mathrm{C} / \mathrm{N}$ 比值结合 $\delta^{13} \mathrm{C}_{\mathrm{org}}$ 是判别物质来源的有效方法 ${ }^{[22-25]}$. 通常情况下, 典型的海洋藻类 $\mathrm{C} / \mathrm{N}$ 比值在 3 8 之间, 陆生高等植被因富含纤维素, 其 $\mathrm{C} / \mathrm{N}$ 比值 $\geqslant 20^{[26-27]}$, 且陆生 $\mathrm{C}_{4}$ 植物比 $\mathrm{C}_{3}$ 植物的 $\mathrm{C} / \mathrm{N}$ 比值 更高 (图 4) ${ }^{[22]}$. Milliman 等 ${ }^{[28]}$ 对长江口多支沉积物岩芯的有机物来源进行了研究, 将 $\mathrm{C} / \mathrm{N}$ 比值大于 12 的 归为陆源有机物, 小于 8 的划分为海源有机物. 此外, 不同来源的有机质碳稳定同位素组成特征会存在显著 差异 ${ }^{[29-33]}$, 典型的海洋植物 $\delta^{13} \mathrm{C}_{\mathrm{org}}$ 值介于 $-19 \% \sim-22 \%$ 之间, 平均值约为 $-20 \%$, 典型的陆源 $\mathrm{C}_{3}$ 植物 $\delta^{13} \mathrm{C}_{\mathrm{org}}$ 的分布范围介于 $-35 \%$ $-20 \%$ 之间, 平均值约为 $-27 \%, \mathrm{C}_{4}$ 植物的 $\delta^{13} \mathrm{C}_{\mathrm{org}}$ 介于 $-14 \%_{0} \sim-9 \%$ 之间, 平均值约 为-13\%. 从 XH15-02 孔柱状样的 $\mathrm{C} / \mathrm{N}$ 比值 $(10.41 \sim 23.33)$ 和 $\delta^{13} \mathrm{C}_{\text {org }}(-25.14 \%$ - 23.29\%o) (图 4) 的分布可 以看出, 小海潟湖沉积物中的有机质应该是由海源和陆源混合而成的. 


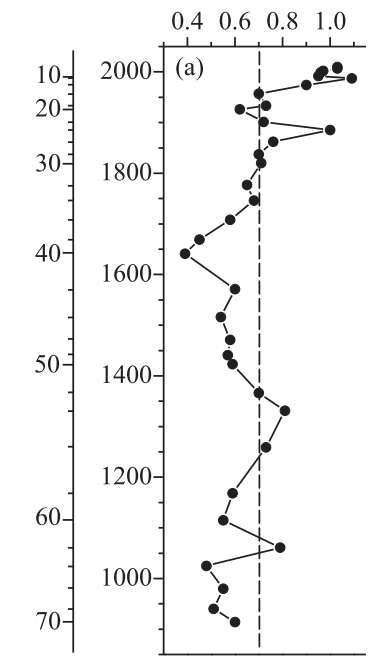

深度/cm 年代/AD TOC $/ \%$

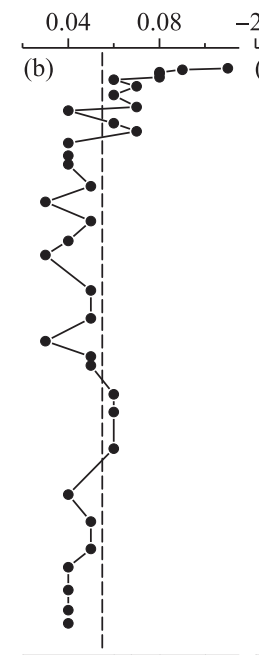

$\mathrm{TN} / \%$
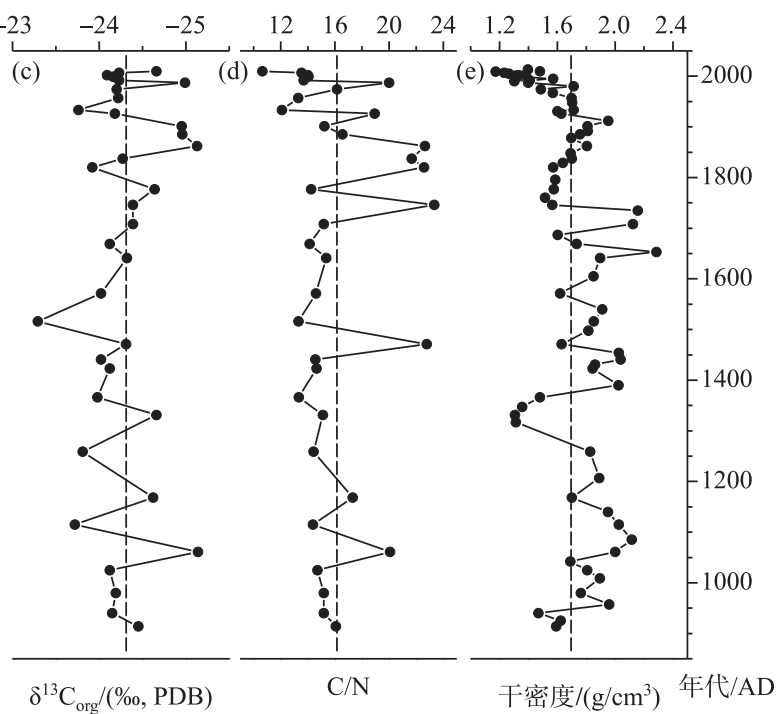

图 3 XH15-02 孔岩芯 TOC、TN、 $\delta^{13} \mathrm{C}_{\text {org }} 、 \mathrm{C} / \mathrm{N}$ 和干密度分析结果

Fig. 3 Variations of TOC, TN $, \delta^{13} \mathrm{C}_{\text {org }}, \mathrm{C} / \mathrm{N}$ ratio and dry density records in XH15-02 core

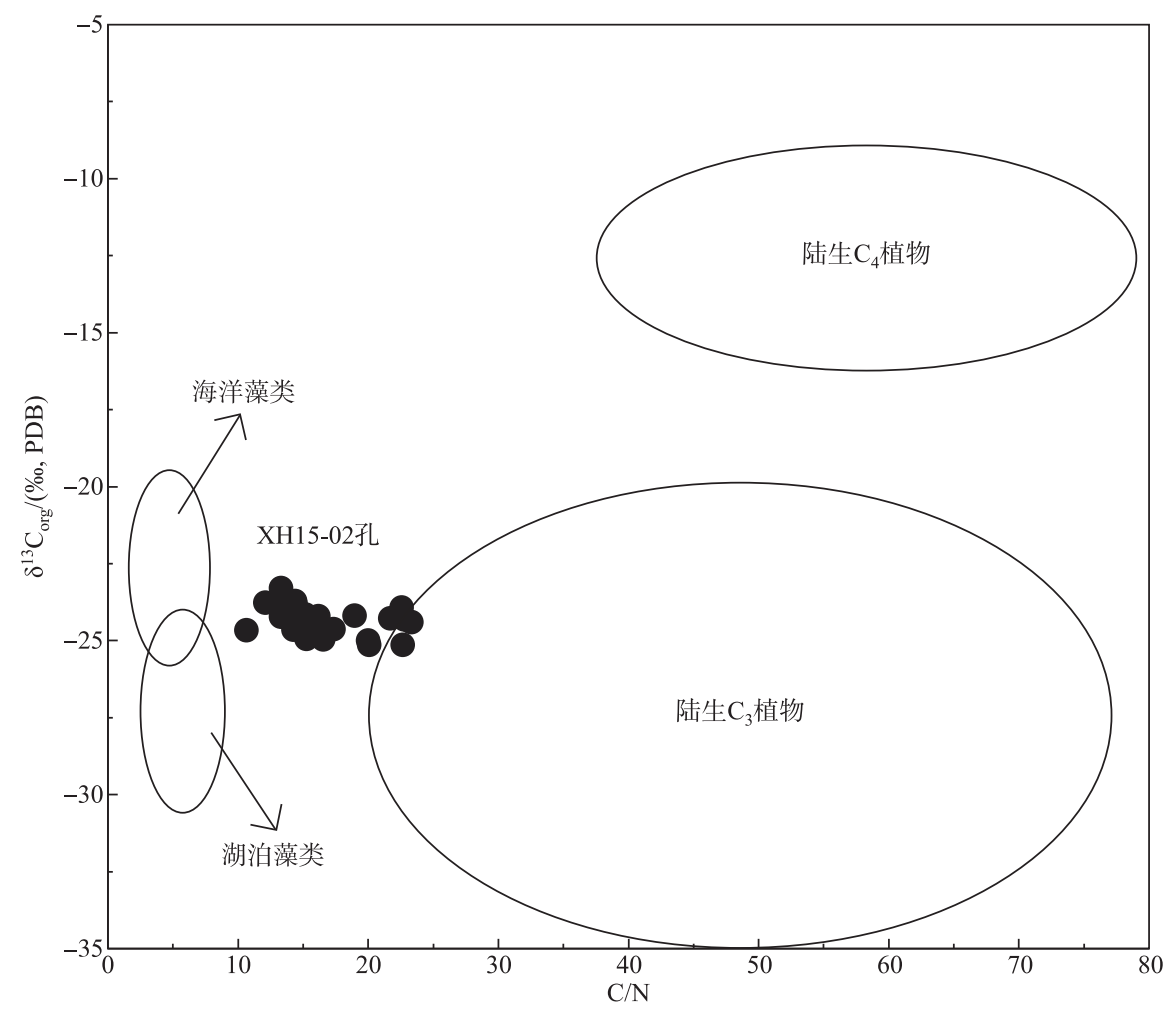

图 4 XH15-02 孔岩芯 $\delta^{13} \mathrm{C}_{\text {org }}$ 和 $\mathrm{C} / \mathrm{N}$ 比值 (图中黑点所示) 与

典型海洋和陆生植被 $\delta^{13} \mathrm{C}_{\text {org }}$ 和 $\mathrm{C} / \mathrm{N}$ 比值分布范围 ${ }^{[22]}$ 的比较

Fig. $4 \mathrm{C} / \mathrm{N}$ ratio and $\delta^{13} \mathrm{C}_{\text {org }}$ values in the sediment of XH15-02 core,

and in comparison with typical values of marine and lacustrine algae and land plants ${ }^{[22]}$ 
不同来源 (海源或陆源) 的有机碳所占比例的估算则相对较为复杂, 大多借助于沉积物 $\mathrm{C} / \mathrm{N}$ 比值或者 $\delta^{13} \mathrm{C}_{\text {org }}$ 来做估算 ${ }^{[34-36]}$. 运用 $\mathrm{Wu}$ 等 ${ }^{[36]}$ 提出的经验公式 (利用沉积物 $\delta^{13} \mathrm{C}_{\text {org }}$ 估算陆源和海源有机碳占比) 计算 了 XH15-02 柱状样中有机物的陆源有机碳占总有机碳的比例, 结果如图 5 所示. 从图 5 可以看出, XH15-02 岩芯沉积陆源有机碳占总有机碳的比例最多的年份可达 $73.4 \%$, 占比最小的年份约为 $47 \%$, 平均而言, XH15-02 岩芯中陆源有机碳占 60\% 左右, 海源有机碳约占 40\%. 此外, 本文也尝试利用 C/N 比值法 ${ }^{[34-35]}$ 估算 了 XH15-02 柱状样中的陆源有机碳占比, 发现依据该方法估算得到的陆源有机碳含量占比较根据同位素方 法 $^{[36]}$ 重建的结果变幅偏大, 个别年份甚至超过了 $100 \%$. 相较 $\mathrm{C} / \mathrm{N}$ 比值法而言, $\mathrm{Wu}$ 等 ${ }^{[36]}$ 采用的经验公式利 用的是沉积物 $\delta^{13} \mathrm{C}_{\text {org }}$, 因同位素不易受粒度、生物活动等的影响, 重建的结果似乎更为合理 ${ }^{[37]}$. 总的来看, 近 千年来, 小海沉积物中有机碳来源表现出明显的波动变化, 陆源有机碳占总有机碳比例最大的时期约在 $1061 \mathrm{AD}$ 前后, 海源有机碳来源占比最大的时期约为 $1520 \mathrm{AD}$. 值得指出的是, 在 1350-1850 AD 期间, 小海 潟湖沉积物中陆源有机碳占比总体上偏低 (图 5), 可能与小冰期 (Little Ice Age) ${ }^{[38]}$ 期间研究区降水有所减 少有关.

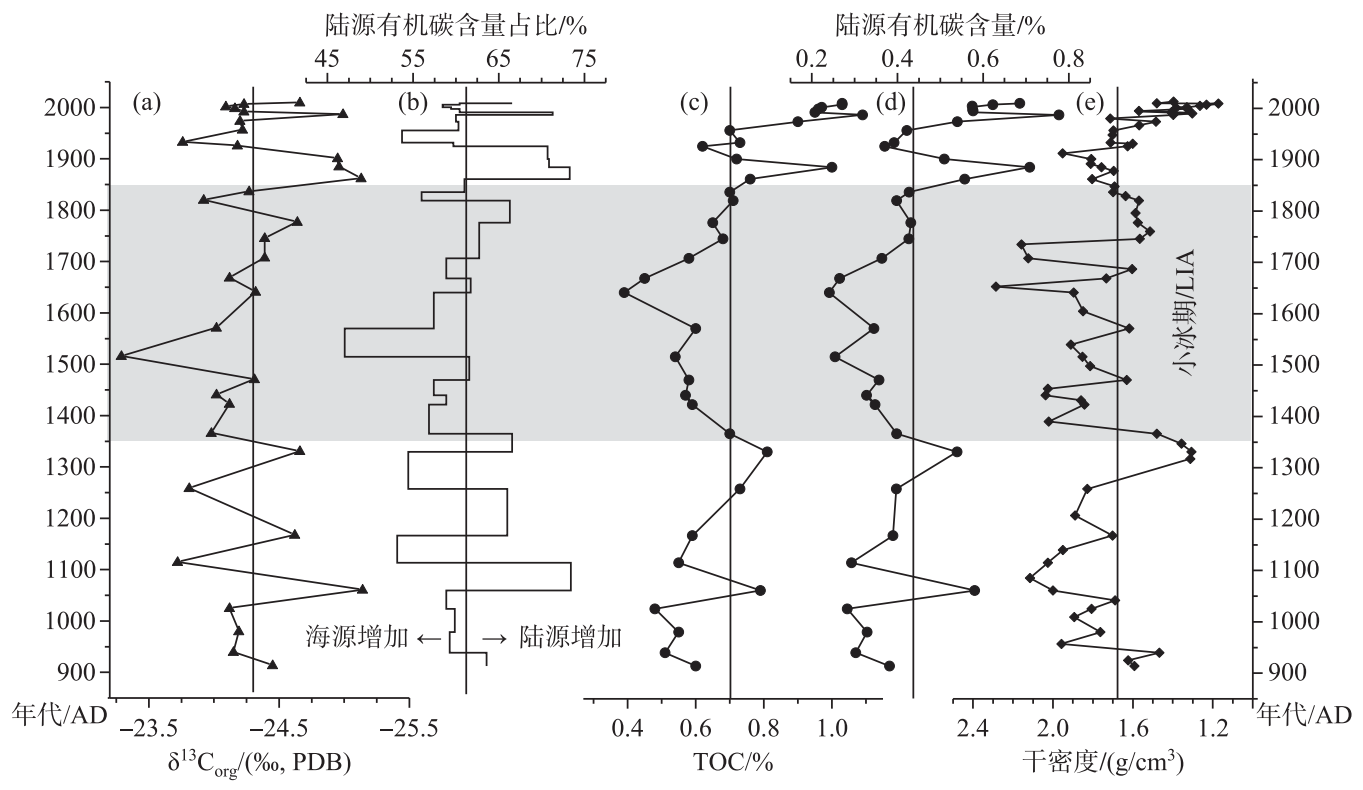

图 5 XH15-02 孔岩芯多气候环境代用指标的对比

Fig.5 Comparison of multi-proxies records of the XH15-02 core

大量研究表明, 流域内植被的生长或者覆盖状况主要受气温、降水或相对湿度的影响. $\mathrm{Li}$ 等 ${ }^{[39]}$ 基于孢 粉数据定量重建了中国北方地区过去 2200 年以来的气温和降水变化, 结果显示, 在过去 2200 年中中国北方 地区的气温变化幅度在 $2^{\circ} \mathrm{C}$ 以内; $\mathrm{Ge}$ 等 ${ }^{[40]}$ 重建的中国过去 2000 年的气温序列也显示, 近 2000 年的气温变 化幅度很小; 即便在温差相对较大的冬季, 中国东部的平均温度变化也在 $3^{\circ} \mathrm{C}$ 以内 ${ }^{[41]}$. 小海潟湖地处我国热 带北缘, 年均温在 $24^{\circ} \mathrm{C}$ 以上, 热量充足, 多年气温变幅相对较小. 考虑到近 2000 年来中国不同地区已有的气 温重建记录变幅以及海南小海所处的地理位置, 该地区在过去千年期间的气温变化幅度应该不大, 应不足 以显著改变(减少)植被的生长或覆盖状况, 因而, XH15-02 孔岩芯陆源有机碳含量在 1350-1850 AD(小冰 期期间) 表现出的相对低值很可能主要受当地降水变化影响, 即该时期降水量有所减少, 导致流域内地表植 被生产力 (覆盖度) 降低, 从而使得随河流搬运人湖的陆源有机碳含量减少. 实际上, 与小冰期期间陆源有机 碳含量的低值相对应, 该时期岩芯的干密度指标 (图 5) 和同一钻孔 $>63 \mu \mathrm{m}$ 的砂含量 ${ }^{[42]}$ 均表现为相对高值, 支持前述的分析. 由此认为, XH15-02 孔岩芯陆源有机碳含量变化很可能反映了海南东部地区过去千年的 降水变化, 即在陆源有机碳含量高值期, 降水相对丰富, 而在陆源有机碳含量较低的时期, 降水相对减少. 


\section{2 小海西南部沉积物沉积通量和有机碳沉积通量变化}

由图 6 可知, 小海西南部沉积物的沉积通量与有机碳沉积通量变化非常一致. 具体来看, 1850 年之前, 沉积物沉积通量范围为 $0.305 \sim 2.633 \mathrm{~g} /\left(\mathrm{cm}^{2} \cdot \mathrm{a}\right)$, 平均值为 $0.931 \mathrm{~g} /\left(\mathrm{cm}^{2} \cdot \mathrm{a}\right)$, 有机碳沉积通量范围为 $0.002 \sim$ $0.012 \mathrm{~g} /\left(\mathrm{cm}^{2} \cdot \mathrm{a}\right)$, 平均值为 $0.005 \mathrm{~g} /\left(\mathrm{cm}^{2} \cdot \mathrm{a}\right)$, 二者都比较小且保持稳定, 仅在 $1423-1454 \mathrm{AD}$ 期间表现为 明显峰值; 1850 年之后两者波动变化比较大 (分别介于 $1.302 \sim 13.830$ 和 $0.009 \sim 0.087 \mathrm{~g} /\left(\mathrm{cm}^{2} \cdot \mathrm{a}\right)$ 之间, 平均 值分别为 5.01 和 $0.040 \mathrm{~g} /\left(\mathrm{cm}^{2} \cdot \mathrm{a}\right)$, 其中沉积物沉积通量在约 1878-1892 AD 和 1926-1931 AD 期间表现 为明显峰值, $1950 \mathrm{~s}$ 以后两者均表现为显著上升趋势, 表明这些时期潟湖西南部沉积物质的大量增加. 这种 沉积特征的明显变化除了可能与自然因素 (诸如台风、洪水事件等)有关之外, 可能与近 200 年来海南地区 人口数量的增加以及随之而来的人类活动对自然界的影响逐渐增强具有很大关系.

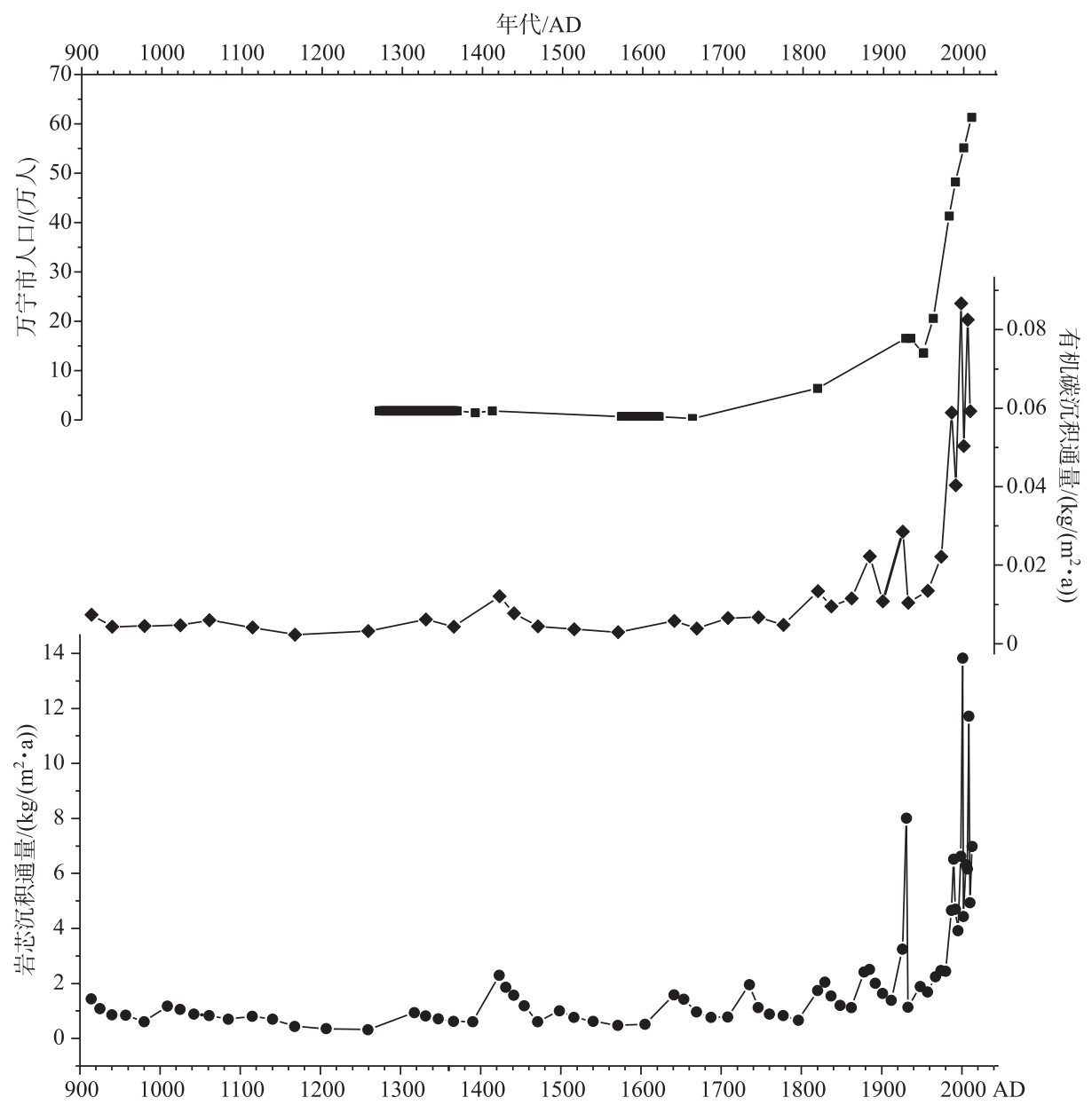

图 6 XH15-02 孔岩芯沉积通量、有机碳沉积通量与万宁市人口变化 ${ }^{[44]}$ 的对比

Fig. 6 Comparison of the sediment fluxes and organic carbon sediment fluxes of the XH15-02 core with the population of Wanning City ${ }^{[44]}$

XH15-02 孔岩芯沉积通量变化在 1850 年之后的持续上升过程中有两个明显的峰值期, 结合史料记 载 ${ }^{[43]}$ 分析认为, 1926-1931 AD 时期较高的沉积速率、沉积物和有机碳沉积通量可能与该时期较为频繁的 台风活动及其带来的强降水有关. 有资料记载 ${ }^{[43]}, 1933$ 年, 万宁“ 11 月 $1 、 2 、 3 、 4$ 日 (九月十四、十五、十六、 十七), 大雨滂沱, 至 5 日 (九月十八) 晨, 忽吹䢐风, 县城各机关屋宇、县政府、县中学等吹塌, 民房十之八九 倒塌; 附城第一区平地水深五六尺, 多日未退, 禾谷初受风灾, 继被水淹, 民众牲畜杂物水冲溺毕不知凡几”; 
该记载与前述沉积通量峰值出现的时间 (约 1931 年) 相近. 在约 1926-1931 AD 时期,沉积物沉积通量为高 值, 同一钻孔的粉砂含量 ${ }^{[42]}$ 也表现为高值. 根据《中国海湾志 - 第十一分册 (海南省海湾) $\rangle^{[16]}$ 的研究认为, 小海潟湖泥沙大致有 3 个来源, 分别是来源于东岸沙坝由风力吹扬和雨水冲刷而来的坝上泥沙、潮流由北 部通道携带来的泥沙以及陆地径流在雨季特别是洪水季节携带而来的泥沙. 考虑到 XH15-02 孔岩芯采样点 位于小海潟湖的西南部, 距离东部沙坝海岸和东北部的口门较远, 且该潟湖最大的补给径流太阳河也是从 潟湖西南部人湖, 在台风强降水期间由河流搬运而来的陆源物质大量增加可能是导致这一时期沉积通量以 及有机碳沉积通量显著增加的重要原因. 另一个沉积通量峰值期大约出现于 1878-1892 AD 时期, 此时陆 源有机碳输人占比和有机碳含量均有显著增加 (图 5). 通常沉积物的快速沉积可能与台风、洪水等事件有 关, 但查阅史料文献 ${ }^{[43]}$ 并没有发现关于该时期该地区旱灾、风灾或者洪水发生的记载, 反而是查阅海南省各 县县志 ${ }^{[44]}$ 发现该时期各地人口普遍有显著增加, 据此推测, 1878-1892 AD 时期的快速沉积可能与该时期 海南地区人口大量增加进而人类活动开发强度增强有关. 1818 年以前, 万宁市人口数量相对较少, 之后人口 显著增加 (图 6). 人口数量的多少直接关系到自然资源的开发程度、利用方式和规模大小, 对自然环境的改 造程度加强会影响到土壤侵蚀和植被破坏程度, 使得径流可携带的物质增加, 进而使得沉积物沉积通量和 有机碳沉积通量都随之增加, 同一时期 XH15-02 孔岩芯中 $>63 \mu \mathrm{m}$ 的砂含量 ${ }^{[42]}$ 也较高. 因而, 岩芯沉积物沉 积速率和沉积通量及有机碳沉积通量在 1850 年之前都比较小且稳定, 可能与该时期人口数量较少从而对 自然环境的影响较弱有关, 而 1850 年之后沉积物沉积通量及其波动幅度均变大, 可能主要与同时期以万宁 为代表的海南各地区人口显著增加有关 (图 6). 此外, 自 20 世纪 50 年代特别是 80 年代末以来, 沉积物沉积 通量和有机碳沉积通量也均呈现出快速上升的趋势, C/N 比值下降、TOC、TN 含量显著增加, 这种快速上升 在海南东南部的新村潟湖等其他海岸潟湖中也均有体现 ${ }^{[4,45]}$, 可能与该时期的人类耕作、水产养殖、城镇建 设等人类活动增强有关 ${ }^{[46]}$.

\section{3 小海沉积物对历史时期强台风活动的可能指示意义}

海岸潟湖沉积物 $\delta^{13} \mathrm{C}$ 值已被成功用来识别台风(县风) 活动. Lambert 等 ${ }^{[47]}$ 以 $1717 \mathrm{AD}$ 的 “Pénicaut's Storm” 为例, 分析了风䢐风时期 Shelby 湖有机质碳、氮同位素的变化特征,认为有机碳、氮同位素显著偏正能 够指示强县风带来的海水侵人, 并据此提取了该地区过去 682 年的灾害性县风信息. Das 等 ${ }^{[7]}$ 也曾根据海岸 地区沉积物中偏正的碳同位素值与典型海洋物质输人增加的关系, 识别出地化元素中隐藏的风俱风/海啸事 件, 重建了佛罗里达州西北海岸近 4000 年来的台风/海啸变化过程. 实际上, 在台风 (䢐风) 期间, 台风会带 来大量降水, 使得湖泊水量骤增, 大量水流人海或者台风引起的高海浪猛烈冲刷口门, 导致湖泊与外部水体 交换通道扩大, 随之人湖潮流增加. 入湖海水的增加会带来更多的营养物质, 使潟湖环境更适宜海洋藻类的 生长, 随海水增加而带来的大量无机碳使植物光合作用中的无机碳源增加, 分馏过程中碳同位素偏重, 因而 海水的增加能够使潟湖沉积物 $\delta^{13} \mathrm{C}_{\text {org }}$ 值偏正 ${ }^{[47]}$. 前已述及, XH15-02 孔岩芯沉积物 $\delta^{13} \mathrm{C}_{\text {org }}$ 值在多个时期明显 增大, 海源有机碳占比显著增加, 表明这些时期小海潟湖更加偏向海洋生态环境. 由图 5 中 $\delta^{13} \mathrm{C}$ 值变化序列 以及据 $\delta^{13} \mathrm{C}$ 值推算的陆源有机碳占比可知, 大约在 $1025 、 1115 、 1254 、 1366 、 1423 、 1441 、 1520 、 1571 、 1669$ 、 1820、1933 AD 等时期, XH15-02 孔岩芯沉积物 $\delta^{13} \mathrm{C}$ 值较为偏正、陆源有机碳占比偏少 (海源有机碳占比增 加), 可能意味着这些时期曾发生过能够引起海洋来水显著增加的活动或事件 (如台风活动或海平面升高), 尤其是上述多个时期与历史文献记载中的海南东部地区一些“大风”、“海溢”、“县大作”等灾害事件的记载 时间较为接近. 举例来说, 如 $1520 \mathrm{AD}$ 前后 $\delta^{13} \mathrm{C}$ 值最高, 海源有机碳占比最多, 就可能是由于这一时期人湖 海水水量显著增加造成. 根据史料记载 ${ }^{[43]}, 1524 \mathrm{AD}$ 海南东部 “万州大风, 海溢数十里” (明代时, 万宁称万 州), 考虑到沉积岩芯的年代误差, 该事件可能与岩芯记录的 $1520 \mathrm{AD}$ 前后高 $\delta^{13} \mathrm{C}$ 值期相对应. 史料记载中 “海溢”现象多是由大风(史料中尚没有 “台风” 的说法, 多记为“大风”、“县风”) 活动造成, 大风天气给当地 带来大量降水, 导致流域内洪水快速人湖, 而潟湖水体因受海水顶托, 短时间内无法将大量来水排出, 与此 同时, 大量水流从潟湖排出将加大对口门通道的冲刷使得口门通道的淤积减少, 这又会反过来进一步增加 入湖的海水量. 入湖海水的增加会带来更多海源物质, 使潟湖环境更适宜海洋藻类的生长, 增加的盐分使植 物光合作用中的无机碳源增加, 当植物以溶解性碳酸氢盐为碳源时, 分馏过程中碳同位素更偏重 ${ }^{[48]}$, 因而增 加的海水输人使 $\delta^{13} \mathrm{C}_{\text {org }}$ 值更偏正. 据此有理由推测, $1520 \mathrm{AD}$ 前后 $\delta^{13} \mathrm{C}$ 值显著偏正可能意味着该时期潟湖 
受海水影响增加、潟湖偏向海洋环境, 可能与该时期台风活动频繁有关. 将 XH15-02 孔岩芯沉积 $\delta^{13} \mathrm{C}_{\text {org }}$ 值记 录所揭示的偏海洋生态环境变化的时期与史料记载 ${ }^{[43]}$ 作进一步的对比分析, $\delta^{13} \mathrm{C}$ 值偏正的 $1423 \mathrm{AD}$ 前后与 大风 (台风) 活动引起海水涨溢的 $1423 \mathrm{AD}$ 琼州 (与万宁相距仅数十公里) “海水涌溢” 记载时间相近; $\delta^{13} \mathrm{C}_{\text {org }}$ 值偏正的 1571 、1820 AD 前后分别与 $1572 \mathrm{AD}$ 万州 “大慁风,海水溢”、1818 AD 万州“县大作,海水涨溢” 的 时间相近, $1933 \mathrm{AD}$ 前后海南也遭遇了严重的台风强降水灾害. 此外, $\delta^{13} \mathrm{C}$ 值偏正的 $1025 \mathrm{AD}$ 前后与袭击西 沙东岛的 $1024 \mathrm{AD}$ 前后的超强台风 ${ }^{[49]}$ 发生时间相近; 1064 $\pm 30 、 1336 \pm 9 \mathrm{AD}$ 南海周边地区也曾发生了大的风 暴/海啸 ${ }^{[50]}$, 在时间上基本能够与 XH15-02 岩芯 $\delta^{13} \mathrm{C}_{\text {org }}$ 值偏正的 $1115 \pm 30 、 1366 \pm 30 \mathrm{AD}$ 时期相对应; $\delta^{13} \mathrm{C}$ 值 偏正的 $1441 \mathrm{AD}$ 前后与南海珊瑚块记录的 $1443 \pm 9$ 年的强风暴/海啸 ${ }^{[50]}$ 时期相近. 有点特别地是, 在大约 $1254 \mathrm{AD}$ 前后, 小海沉积物 $\delta^{13} \mathrm{C}_{\text {org }}$ 值较其他时期的 $\delta^{13} \mathrm{C}_{\text {org }}$ 值更为偏正, 但在史料记载或其他文献中并未发现 该时期海南或南海地区有台风或者海啸发生的记录. 聂宝符等 ${ }^{[51]}$ 曾报道雷州半岛南端高于现代海平面的 最年轻的一个原生珊瑚礁的 ${ }^{14} \mathrm{C}$ 年代值为 $1170 \mathrm{a} \mathrm{BP}$, 转化为日历年龄约为 $700 \mathrm{cal} . \mathrm{a} \mathrm{BP}{ }^{[52]}$, 即 $1250 \mathrm{AD}$, 这与 本文中 XH15-02 孔岩芯 $\delta^{13} \mathrm{C}_{\text {org }}$ 值显著偏正的 $1254 \mathrm{AD}$ 前后非常相近, 可能意味着 1254 AD 前后 XH15-02 孔 岩芯的 $\delta^{13} \mathrm{C}_{\text {org }}$ 高值期很可能与该时期南海海平面阶段性升高有关. 考虑到岩芯沉积的年代误差, 上述 $\delta^{13} \mathrm{C}_{\text {org }}$ 值显著偏正的时期与历史文献记载以及其他地质载体记录的台风或风暴、海啸事件以及阶段性高海平面发 生时期较为吻合, 表明小海潟湖沉积物在重建历史时期海南地区的台风或风暴活动等方面具有很大潜力.

\section{5 结论}

对采集于海南东部小海潟湖的 XH15-02 柱状岩芯进行了 ${ }^{210} \mathrm{~Pb}$ 和 $\mathrm{AMS}^{14} \mathrm{C}$ 测年, 开展了 $\mathrm{TOC} 、 \mathrm{TN} 、 \delta^{13} \mathrm{C}_{\text {org }}$ 等环境代用指标的测试,探讨了该柱状岩芯沉积物有机地球化学特征及其可能的气候环境指示意义,进而 揭示了近千年以来小海潟湖及其周边地区的气候环境变化及历史时期的台风活动信息. 结果表明, XH15-02 孔岩芯沉积物中有机质为混合来源, 主要以陆生 $\mathrm{C}_{3}$ 植物和海洋藻类组成, 有机碳多数时期以陆源输人为主, 陆源有机碳含量在 1350-1850 $\mathrm{AD}$ (小冰期) 期间占比相对较少, 这很可能与小冰期期间海南地区降水有所 减少进而导致流域地表植被生产力或覆盖度降低有关. XH15-02 孔岩芯沉积通量和有机碳沉积通量在 1850 年之前较小且较为稳定, 在 1850 年之后两者均快速增加, 可能与近千年来海南地区人口数量的变化历史尤 其是近两百年来人口迅速增加导致人类活动对自然环境的开发、影响增强具有很大关系. 通过对比分析 XH15-02 孔岩芯沉积记录和海南地区史料记载以及南海周边其他地质沉积记录发现, $\delta^{13} \mathrm{C}_{\text {org }}$ 值显著偏正时 期与历史文献记载的海南地区多个台风(史料中多称为 “大风”、墈风”) 频发时期非常相近, 与来自南海多 个岛屿湖泊或潟湖的地质沉积记录的风暴/海啸事件发生时间也较为接近, 表明小海潟湖沉积物在重建历 史时期海南地区的台风或风暴活动等方面具有很大潜力, 该潟湖沉积 $\delta^{13} \mathrm{C}_{\mathrm{org}}$ 可以作为重建历史时期海南地 区台风活动的重要替代指标.

\section{6 参考文献}

[ 1 ] Koop K, Larkum AWD. Deposition of organic material in a coral reef lagoon, One Tree Island, Great Barrier Reef. Estuarine Coastal \& Shelf Science, 1987, 25(1) : 1-9. DOI: 10.1016/0272-7714(87)90021-7.

[ 2 ] Ryan KE, Walsh JP, Corbett DR et al. A record of recent change in terrestrial sedimentation in a coral-reef environment, La Parguera, Puerto Rico: A response to coastal development. Marine Pollution Bulletin, 2008, 56 (6) : 1177-1183. DOI: 10.1016/j.marpolbul.2008.02.017.

[ 3 ] Zhou L, Gao S, Yang Y et al. Sediment accumulation and carbon burial in two tropical lagoons, Southeastern Hainan Island. Quaternary Sciences, 2016, 36(1): 66-77. [周亮, 高抒, 杨阳等. 海南岛东南部海湾潟湖沉积和碳埋藏变化 研究. 第四纪研究, 2016, 36(1) : 66-77.]

[ 4 ] Zhou L, Gao S, Gao J et al. Reconstructing environmental changes of a coastal lagoon with coral reefs in southeastern Hainan Island. Chinese Geographical Science, 2017, 27(3) : 402-414. DOI: 10.1007/s11769-017-0867-9.

[ 5 ] Zhao N, Yang Y, Gao JH et al. The influences of natural and human activities on sources and evolution of organic matter in the Yuehu Lagoon sediments. Geochimica, 2014, 43(4): 365-374. [赵宁, 杨昒, 高建华等. 自然和人类活动作用下 月湖沉积物有机质来源及其演变. 地球化学, 2014, 43(4) : 365-374.] 
[ 6 ] Storms JEA, Weltje GJ, Terra GJ et al. Coastal dynamics under conditions of rapid sea-level rise: Late Pleistocene to Early Holocene evolution of barrier-lagoon systems on the northern Adriatic shelf (Italy). Quaternary Science Reviews, 2008,27 (11) : 1107-1123. DOI: 10.1016/j.quascirev.2008.02.009.

[ 7 ] Das O, Wang Y, Donoghue J et al. Reconstruction of paleostorms and paleoenvironment using geochemical proxies archived in the sediments of two coastal lakes in northwest Florida. Quaternary Science Reviews, 2013, 68(3) : 142-153. DOI: $10.1016 /$ j.quascirev.2013.02.014.

[ 8 ] Wu H, Lin X, Wu SA et al. Change characters of landing Hainan Island tropical cyclones in 1949-2005. Journal of Meteorological Research and Application, 2010, 31(3) : 9-12. [吴慧, 林熙, 吴胜安等. 1949-2005 年海南岛登陆热带气 旋的若干变化特征. 气象研究与应用, 2010, 31(3): 9-12.]

[ 9 ] Guo LF, Zhong JL. Geochemical characteristics of sediments from Xiaohai Lagoon, Hainan Island. Tropic Oceanology, 1989, 8(3) : 27-35. [ 郭丽芬, 钟晋梁. 海南岛小海潟湖沉积物的地球化学特征. 热带海洋学报, 1989, 8(3): 27-35. ]

[10] Liu XJ, Ge CD. Sedimentary environment evolvement of Xiaohai Lagoon in the Hainan Island. Marine Science Bulletin, 2007, 26(4) : 71-79. [刘兴健, 葛晨东. 海南岛小海潟湖沉积环境演变研究. 海洋通报, 2007, 26(4): 71-79.]

[11] Liu XJ, Ge CD, Chen PP et al. Anthropogenic impact on the sedimentary environment of Xiaohai Lagoon, Hainan Island. Environmental Chemistry, 2007, 26(3) : 384-387. [刘兴建, 葛晨东, 陈平平等. 人类活动对海南省小海潟湖沉积环 境的影响. 环境化学, 2007, 26(3): 384-387.]

[12] Tian XP, Li CC. The environmental disruption and transformation of Xiaohai lagoon in Hainan. Marine Environmental Science, 2007, 26(1) : 91-94. [田向平, 李春初. 海南小海潟湖环境的破坏与治理. 海洋环境科学, 2007, 26(1) : 91-94.]

[13] He W, Li CC, Shen HK et al. Study on the treatment plan of Xiaohai Lagoon channel in Hainan Island. Pearl River, 2005, 26(a02) : 28-30. [何为, 李春初, 沈汉埥等. 海南岛小海潟湖通道治理方案研究. 人民珠江, 2005,26 ( a02) : 28-30.]

[14] Yu K. Flood tide characteristics and main factors of flood water level in Hainan Xiaohai. Guangdong Water Resources and Hydropower, 2014, (3) : 51-56. [俞琨. 海南小海洪潮特性及洪水位主要影响因素研究. 广东水利水电, 2014, (3) : 51-56.]

[15] Wang SJ, Li CC, Tian XP. Self-adjustment and deterioration of Xiaohai barrier-lagoon-tidal inlet system in Hainan Island. Journal of Oceanography in Taiwan Strait, 2003, 22(2): 248-253. [王世俊, 李春初, 田向平. 海南岛小海沙坝-泻 湖-潮汐通道体系自动调整及恶化. 台湾海峡, 2003, 22(2): 248-253.]

[16] Compiling Committee of Records of China Bays ed. Records of China Bays 11th Fascicule ( The bays of Hainan). Beijing: Ocean Press, 1999. [中国海湾编纂委员会. 中国海湾志第十一分册(海南省海湾). 北京: 海洋出版社, 1999.]

[17] Goldberg ED, Koide M. Rates of sediment accumulation in the Indian Ocean. Earth Science and Meteoritics, 1963, 1: 90-102.

[18] Charman DJ, Beilman DW, Blaauw M et al. Climate-related changes in peatland carbon accumulation during the last millennium. Biogeosciences, 2013, 10(2) : 929-944.

[19] de Vleeschouwer F, Pazdur A, Luthers C et al. A millennial record of environmental change in peat deposits from the Misten bog (East Belgium). Quaternary International, 2012, 268(4) : 44-57. DOI: 10.1016/j.quaint.2011.12.010.

[20] Blaauw M, Christen JA. Flexible paleoclimate age-depth models using an autoregressive gamma process. Bayesian Analysis, $2011,6(3): 457-474$.

[21] Xie L, Spiro B, Wei G. Purification of $\mathrm{BaSO}_{4}$ precipitate contaminated with organic matter for oxygen isotope measurements $\left(\delta^{18} \mathrm{O}\right.$ and $\left.\Delta^{17} \mathrm{O}\right)$. Rapid Communications in Mass Spectrometry, 2016, 30(14): 1727-1733. DOI: 10.1002/ rem.7610.

[22] Meyers PA. Preservation of elemental and isotopic source identification of sedimentary organic matter. Chemical Geology, 1994, 114(3/4) : 289-302. DOI: 10.1016/0009-2541(94)90059-0.

[23] Meyers PA. Organic geochemical proxies of paleoceanographic, paleolimnologic, and paleoclimatic processes. Organic Geochemistry, 1997, 27(5/6) : 213-250. DOI: 10.1016/S0146-6380(97)00049-1.

[24] Thornton SF, McManus J. Application of organic carbon and nitrogen stable isotope and $\mathrm{C} / \mathrm{N}$ ratios as source indicators of organic matter provenance in estuarine systems: evidence from the Tay Estuary, Scotland. Estuarine Coastal and Shelf Sci- 
ence, 1994, 38(3) : 219-233. DOI: 10.1006/ecss.1994.1015.

[25] Ogrinc N, Fontolan G, Faganeli J et al. Carbon and nitrogen isotope compositions of organic matter in coastal marine sediments (the Gulf of Trieste, N Adriatic Sea): indicators of sources and preservation. Marine Chemistry, 2005, 95(3/4): 163-181. DOI: 10.1016/j.marchem.2004.09.003.

[26] Mayer LM, MacKo SA, Cammen L. Provenance, concentrations and nature of sedimentary organic nitrogen in the gulf of Maine. Marine Chemistry, 1988, 25(3) : 291-304. DOI: 10.1016/0304-4203(88)90056-4.

[27] Stein PDR. Accumulation of organic carbon in marine sediments. Berlin//Heidelberg: Springer-Verlag Heidelberg, 1991: 217-320. DOI: 10.1007/BFb0010382.

[28] Milliman JD, Xie QC, Yang ZS. Transfer of particulate organic carbon and nitrogen from the Yangtze River to the ocean. American Journal of Science, 1984, 284(7) : 824-834. DOI: 10.2475/ajs.284.7.824.

[29] Park R, Epstein S. Carbon isotope fractionation during photosynthesis. Geochimica et Cosmochimica Acta, 1961, 21 (1) : 110-126. DOI: 10.1016/S0016-7037(60)80006-3.

[30] Fontugne MR, Jouanneau JM. Modulation of the particulate organic carbon flux to the ocean by a macrotidal estuary: Evidence from measurements of carbon isotopes in organic matter from the Gironde system. Estuarine Coastal and Shelf Science, 1987, 24(3) : 377-387. DOI: 10.1016/0272-7714(87)90057-6.

[31] Emerson S, Hedges JI. Processes controlling the organic carbon content of open ocean sediments. Paleoceanography, 1988, 3(5) : 621-634. DOI: 10.1029/PA003i005p00621.

[32] O'Leary MH. Carbon isotopes in photosynthesis. Bioscience, 1988, 38(5) : 328-336. DOI: 10.2307/1310735.

[33] Farquhar GD, Ehleringer JR, Hubick KT. Carbon isotope discrimination and photosynthesis. Ann Rev Plant Physiol Plant Mol Biol, 1989, 40(40) : 503-537. DOI: 10.1146/annurev.pp.40.060189.002443.

[34] Qian JL, Wang SM, Xue B et al. A quantitative study method of lake sediments to estimate terrigenous organic carbon. Chinese Science Bulletin, 1997, 42(15) : 1656-1657. DOI:10.1360/csb1997-42-15-1655. [钱君龙, 王苏民，薛滨等. 湖泊沉积研究中一种定量估算陆源有机碳的方法. 科学通报, 1997, 42(15) : 1656-1657.]

[35] Jia GD, Peng PA, Fu JM. Sedimentary records of accelerated eutrophication for the last 100 years at the Pearl River Estuary. Quaternary Sciences, 2002, 22(2) : 158-165. [贾国东, 彭平安, 傅家谟. 珠江口近百年来富营养化加剧的沉积 记录. 第四纪研究, 2002, 22(2): 158-165.]

[36] Wu JP, Calvert SE, Wong CS. Carbon and nitrogen isotope ratios in sedimenting particulate organic matter at an upwelling site off Vancouver Island. Estuarine Coastal \& Shelf Science, 1999, 48(48) : 193-203. DOI: 10.1006/ecss.1998.0409.

[37] Wu DD, Ge CD, Gao S et al. Carbon, nitrogen geochemical character and source analyses in Changjiang estuarine sediments. Geochimica , 2012, 41(3): 207-215. [吴丹丹, 葛晨东, 高抒等. 长江口沉积物碳氮元素地球化学特征及有 机质来源分析. 地球化学, 2012, 41(3): 207-215.]

[38] Wang SW, Ye JL, Gong DY. Climate in China during the Little Ice Age. Quaternary Science, 1998, 18( 1):54-64. [王绍 武，叶瑾琳，龚道溢. 中国小冰期的气候. 第四纪研究，1998，18(1):54-64.]

[39] Li J, Dodson J, Yan H et al. Quantifying climatic variability in monsoonal northern China over the last 2200 years and its role in driving Chinese dynastic changes. Quaternary Science Reviews, 2017, 159: 35-46. DOI: 10.1016/j.quascirev.2017. 01.009.

[40] Ge Q, Hao Z, Zheng J et al. Temperature changes over the past $2000 \mathrm{yr}$ in China and comparison with the Northern Hemisphere. Climate of the Past, 2013, 9(3) : 1153-1160. DOI: 10.5194/cp-9-1153-2013.

[41] Ge Q, Zheng J, Fang X et al. Winter half-year temperature reconstruction for the middle and lower reaches of the Yellow River and Yangtze River, China, during the past 2000 years. Holocene, 2003, 13: 933-940.

[42] Li Q. Grain size characteristics and environmental significance of sediments in Xiaohai Lagoon, eastern Hainan [ Dissertation]. Guangzhou: South China Normal University, 2018. [李晴. 海南东部小海潟湖沉积物粒度特征及其环境意义 [学位论文]. 广州: 华南师范大学, 2018.]

[43] Research Institute of Culture and History, the People's Government of Guangdong Province. History of natural disasters in Guangdong province. Guangzhou: Guangdong Science and Technology Press, 1961. [广东省文史研究馆. 广东省自然灾 害史料. 广州: 广东科技出版社, 1961.]

[44] Office of Local Chronicle Compilation of Hainan Province. Local chronicles ( City and county Annals) http://hnszw.org. cn/dfzs.php? Class $=65 \&$ Deep $=2$. [ 海南省地方志办公室.地方志书 $\cdot$ 市县志.http $: / / \mathrm{hnszw} \cdot \mathrm{org} . \mathrm{cn} / \mathrm{dfzs} \cdot \mathrm{php} ? \mathrm{Class}=$ 
$65 \&$ Deep $=2$.

[45] Jia J, Gao J, Liu Y et al. Environmental changes in Shamei Lagoon, Hainan Island, China: Interactions between natural processes and human activities. Journal of Asian Earth Sciences, 2012, 52(4) : 158-168. DOI: 10.1016/j.jseaes.2012. 03.008.

[46] Wanning Municipal Government Office. History and culture. http://wanning. hainan. gov.cn/wngk/200910/t20091008_ 9797.html，2009-10-08. [万宁市政府办. 历史文化. http ://wanning. hainan. gov. cn/wngk/200910/t20091008_9797. html, 2009-10-08. ]

[47] Lambert WJ, Aharon P, Rodriguez AB. Catastrophic hurricane history revealed by organic geochemical proxies in coastal lake sediments: A case study of Lake Shelby, Alabama (USA). Journal of Paleolimnology, 2008, 39(1) : 117-131. DOI: 10.1007/s10933-007-9101-6.

[48] Zhao Y, Wu FL, Chi YP. Application of bulk organic carbon isotope composition for paleoenvironmental research. Journal of Earth Environment, 2013, 4(6) : 1519-1530. DOI: 10.7515/JEE201306006. [赵艳, 吴福莉, 迟云平等. 总有机碳 同位素组成在古环境研究中的应用. 地球环境学报, 2013, 4(6): 1519-1530.]

[49] Sun LG, Liu XD, Zhao SP et al. Sedimentary records: catastrophic marine flooding event occurred on Dongdao Island of South China Sea around 1024AD. Journal of University of Science and Technology of China, 2007, 37( 8) : 986-994. [孙 立广, 刘晓东, 赵三平等. 记录: $1024 \mathrm{AD}$ 前后南中国海最强烈的灾难事件. 中国科学技术大学学报, 2007, 37 (8) : 986-994.]

[50] Yu K, Zhao J, Shi Q et al. Reconstruction of storm/tsunami records over the last 4000 years using transported coral blocks and lagoon sediments in the southern South China Sea. Quaternary International, 2009, 195(1): 128-137. DOI: 10. 1016/j.quaint.2008.05.004.

[51] Nie BF, Chen TG, Lian MT et al. Coral Reef and Holocene High Sea leavel in Leizhou Peninsula. Chinese Science Bulletin, 1997, 42(5) : 510-513. DOI: 10.1360/csb1997-42-5-511. [聂宝符, 陈特固, 梁美桃等. 雷州半岛珊瑚礁与全 新世高海面. 科学通报, 1997, 42(5): 510-513.]

[52] Yu KF, Chen TG. Beach sediments from northern South China Sea suggest high and oscillating sea level during the Holocene. Earth Science Frontiers, 2009, 16(6)：138-145. [余克服, 陈特固. 南海北部晚全新世高海平面及其波动的 海滩沉积证据. 地学前缘, 2009, 16(6): 138-145.] 